\title{
LEADERS AS SHAMANS WORKING TO HEAL A TROUBLED WORLD'
}

\author{
SANDRA WADDOCK \\ Carroll School of Management \\ Boston College \\ Chestnut Hill, Massachusetts, U.S.A. \\ waddock@bc.edu
}

\begin{abstract}
In a world greatly in need of healing, today's leaders acting as shamans could potentially bring the shaman's ancient wisdom to the effort to create a more sustainable, just, and equitable world. Today's shamanic leaders undertake the same roles as the traditional shaman: healing, connecting, and sensemaking in the service of a better world. From a leadership perspective, the shaman's work is that of healing the world around us and our (human) relationship with that world, which is what many leaders are already attempting to do. In this context, healing can mean making our relationships, systems, and organizations whole or sound. In a similar vein, connecting means working across boundaries of different types, such as relationships, disciplines, functions, sectors, and institutions, among others, to create collaborative initiatives or new insights that can move ideas and institutions forward in a positive way. Finally, sensemaking means helping others understand and interpret their world in new and hopefully constructive ways. It means creating a new vision of the future through tasks like developing new memes or framing new stories or narratives that help people relate to their enterprises or the world in different ways. In today's troubled world, where our dominant cultural mythologies, policies, and practices have resulted in frighteningly unsustainable conditions and divisiveness, I argue that more leaders explicitly need to (and can) take on these shamanic roles.
\end{abstract}

Keywords: leadership; shamanic leaders; sustainability; memes

${ }^{1}$ Some of the ideas in this paper are drawn from Intellectual Shamans: Management Academics Making a Difference (Cambridge University Press, 2015) and from The Difference Makers: How Social and Institutional Entrepreneurs Built the Corporate Responsibility Movement (Greenleaf, 2008). 
All traditional cultures typically have their shamans-medicine men and women who help to heal individuals' and communities' ills. Indeed, Peter Frost \& Carolyn Egri call shamanism the world's oldest spiritual tradition (1994). Krippner (2002: 970) cogently notes that shamans "appear to have been humankind's first psychotherapists, first physicians, first magicians, first performing artists, first storytellers, and even the first timekeepers and weather forecasters."

This article argues that there are leaders today who already take on the three core tasks of the shaman-healing, connecting, and sensemaking (Frost \& Egri, 1994; Waddock, 2015a) in the service of a better and more sustainable world. If more did so explicitly, then the many wicked problems facing businesses and other institutions could be dealt with more effectively.

As is obvious to many observers, the world desperately needs the healing that shamanic leaders might be able to provide. Healing, connecting, and sensemaking by leaders can help more people deal with their fears about the future and be able and willing to take necessary actions. Connecting can help us heal our relationships with ourselves, with each other, and with the planet as we learn to listen better, understand more, and act collaboratively from such new bases of insight. Connecting can help bridge divides that exist and heal relationships that now seem intractably problematic. The vital role of sensemaking by leaders can help make sense of the problems of the world-from climate change to political crises to widespread lack of meaningful employment. Sensemaking can help us begin to understand not only what actions are needed but how each person can work toward positive change.

The shamanic work of today's business leaders is not just to make profits but to do the explicitly healing work needed in whatever domains, across whatever boundaries, and in whatever narratives or stories are relevant (e.g., Waddock, 2015a; Frost \& Egri, 1994). We face a context where dominant cultural mythologies sometimes seem terribly askew, where politicians cannot seem to agree on much, where business and other leaders need to move their enterprises toward sustainability and cope with climate change, and where peaceful relationships seem a distant dream. In such a world, leaders acting as shamans are badly needed.

\section{WHY THE SHAMAN?: A CONTEXT OF NEEDED CHANGE}

It is the shaman's capacity for breaking down boundaries and seeing things holistically, or at least from a different perspective than usual, 
that makes the leader's work as shaman particularly crucial today. New and potentially important questions and actions arise out of a way of thinking that links ancient and new ways of knowing, doing, and thinking with present needs. As management scholar Russell Ackoff (1974) argued, the world today desperately needs more wisdom (which seems seriously lacking in far too many domains). In most cultures, shamans are considered the wise elders of their communities, and it is this status that leaders can assume if they embrace their inner shamanic potential.

The world today is confronted with a fraught economic system that has already had one major meltdown in 2007-2008, has fragile ecosystems that are at risk of collapse, social systems where problems abound, political systems filled with divisions, and business/economic systems dominated by financial interests rather than the "real" or productive economy (e.g., Gilding, 2011; Álvarex, 2011; Ehrenfeld \& Hoffman, 2013; IPCC, 2014). These conditions have resulted in popular uprisings around jobs, political instability and divisiveness, growing inequality, terrorist attacks based on misguided fundamentalism(s), and a seeming inability of major institutions and governments to deal with climate change or other significant issues, to name a few.

Such problems, which are complex and chaotic in the mathematical sense, need to be managed holistically rather than piecemeal (Waddell, Waddock, Cornell, Dentoni, McLachlan, \& Meszoely, 2015) to effect change. They demand vision-a systemic understanding of the implications of the issues and creatively imagining a different path. They demand the willingness and courage to take necessary risks to change the way that individual businesses relate to the network of other businesses and institutions with whom they engage. The situation is made more complex because dealing with such wicked problems often demands collaborative approaches that cross a variety of institutional, sectoral, disciplinary, and organizational boundaries. As Ackoff (1974) pointed out, single institutions cannot solve complex or wicked problems, which he termed "messes." If leaders embraced the healing, connecting, and sensemaking roles of the shaman, and were willing to take the associated risks of doing so, the world might be in a better condition. These three roles are briefly explored below.

\section{Healer}

The shaman is, most fundamentally and centrally, a healer (Eliade, 1974; Frost \& Egri, 1994; Dow, 1986). The word "healing" has the same root as the words "whole," "healthy," and "holy," meaning to make sound, whole, or have integrity. Traditional shamans typically do their 
healing at the level of the individual patient who is dis-eased (the hyphen is added to suggest a distinct unease with something in the world) or dis-ordered (out of order) in some way that manifests itself as illness.

Leaders as shamans might work to make whole and evidence integrity, to heal their teams, enterprises, communities, other types of institutions, and even the world at large. Particularly in need of such healing are human beings' and their enterprises' relationships with nature, which as the climate change and sustainability crises suggest are highly problematic. The idea of the healing function, then, is that it is purposively directed at making something healthier, better, or more "whole," i.e., having integrity.

The central task of healing for the leader as shaman is supported by the other two functions of connecting and sensemaking.

\section{Connector}

To do their healing work, traditional shamans "journey" to different (mostly spiritual) realms and connect across them, often believing that they are connecting with a universal spirit (or specific spirits, guides, or gods) to get information (e.g., Harner, 1990; Villoldo, 2007; Walsh, 2014). Shamans go to these other realms to gather and bring back information, insights, and knowledge for healing purposes, and in doing so they span boundaries of different types. Perhaps, in more psychological terms, they are tapping into what psychologist Carl Jung called the collective unconscious (Jung, 1936, 1981). Perhaps they are tapping into their intuitions, instincts, and creative impulses for inspiration, connections that others have not yet made, along with new ideas that can be used in a variety of ways. Leaders in enterprises do this boundary-spanning when they engage with stakeholders to learn about their interests and needs. They do it when they integrate across functions to gain multiple inputs from projects, services, and products, and when they create alliances of various sorts.

Shamans as connectors are what Frost \& Egri (1994) called mediators of realities-they bridge across different "non-ordinary" worlds. These realms are spiritual for traditional shamans, and tend to be intellectual or disciplinary for intellectual ones (Waddock, 2015a). For leaders acting in the so-called real world, boundaries between realms can be interpersonal, intrapersonal, sectoral, functional, organizational, and institutional.

The connecting function takes leaders as shamans to non-ordinary realms in that they have to enter into the worlds or perspectives of others 
quite different from themselves. There they try to understand those different perspectives, and bring back new information, insights, and connections that might not otherwise be made. Thus, by "connecting the dots" across boundaries, leaders as shamans take a systemic or holistic perspective on situations. They make linkages across ideas, insights, and institutions. They quite deliberately go out into worlds that are "different" from their own to experience new things and gain insights not available to them in their "ordinary" realms.

Through connecting activities, traditional shamans seek and bring back information that helps heal a sick patient. They often accomplish this task by healing or reframing the cultural mythologies that help to frame the community's understanding of the world about them. These myths, when problematic, are believed to be the source of dis-ease and dis-order in the community (Dow, 1986).

Today's leaders as shamans also need to bridge realms of practice in various ways to gather and bring back information that provides new insights, helps heal rifts, or builds new narratives and stories, i.e., new cultural myths (Dow, 1986). Such bridging provides for new insights that are gained by understanding and integrating multiple perspectives. For business leaders to truly understand stakeholders' perspectives, for example, means to enter into the world and mindsets of people different from the self to better understand what is meaningful and important to them, and then acting on the basis of that new understanding.

Business leaders operating as shamans today may need to find ways to develop cross-sector collaborations with activists to bring new information and points of view into their enterprises and help them avoid problems. They may need to work with multiple stakeholders to get the latter's perspectives on the company and its products or services. Or they may integrate strategies and ideas across multiple functional areas to ensure new products and services are developed effectively, or work with other leaders in coalitions to begin to cope with the types of big social concerns that are represented, for example, by the wicked problems of sustainability, inequality, and climate change, among others (Churchman, 1967; Rittel \& Webber, 1973). By their nature, such issues demand more integrated and holistic approaches (e.g., Ackoff, 1974; Waddell et al., 2015). Such approaches tend to be cross functional, multi-disciplinary, or multi-organizational, demanding the systemic or holistic perspective characteristic of the shaman (Frost \& Egri, 1994; Waddock, 2015a). 


\section{Sensemaker}

Since the shaman in traditional cultures believes that people get sick when there is something wrong in the mythologies that help frame that culture, the mythology or dominant cultural narrative needs to change to enable the patient to get well (Dow, 1986). Shamans (and, not incidentally, leaders as strategists) are also sensemakers, serving in a sense as spiritual leaders by providing guidance and helping frame things for others (Frost \& Egri, 1994; Weick, Sutcliffe, \& Obstfeld, 2005). Through sensemaking, leaders as shamans shape new narratives and the memes that support them (Blackmore, 2000; Waddock, 2015a). For instance, new narratives are often needed for reframing a leader's activities for the organization, creating new visions and strategies, or helping others understand where the enterprise stands. Sometimes sensemaking brings new ideas to light.

Changing cultural narratives, especially when they are causing problems, is a central task of the shaman as sensemaker (see Dow, 1986) and of many of today's leaders. Acting as shamans, they could be the ones who take and synthesize information from different realms (which could be sectors, different types of institutions or organizations, or different stakeholders) in new ways. Using this information gathered from different sources (and connecting these ideas in new or insightful ways), they can begin to generate creative new insights that can be used to heal broken cultural myths (such as those of institutions, ideas, narratives, and strategies). Through sensemaking activities from a sustainability perspective, for example, such leaders are acknowledging the narratives whose influences are making our economic and social systems "ill" and impeding the planet's ability to support human civilization (e.g., Gilding, 2011; Ehrenfeld \& Hoffman, 2013; IPCC, 2014).

Many of the issues facing businesses and societies need new and innovative approaches that are holistic and collaborative, which are core aspects of the way shamans as leaders operate in the world. Creating significant change, for example, can mean using the sensemaking capacity to develop new memes (Dawkins, 2006) that support new narratives which shape perspectives and worldviews that are different from currently dominant ones. Memes-phrases, words, images, and symbols-are the foundational units of cultural norms, and can help shape attitudes, belief systems, and narratives that frame how people see the world (or enterprises) (Blackmore, 2000; Dawkins, 2006; Waddock, 2015a). Ideas as memes, which replicate themselves when successful, can be powerful ways to begin a change process (Waddock, 2015b), particularly when they are holistic yet concise. They can inspire and reshape understanding of the world (or of local mythologies). 
Ultimately, memes and narratives shape behaviors and practices in important ways (Waddock, 2015b; Dawkins, 2006) because they shape perspectives on what our relationship with and place in the world is (Blackmore, 2000).

Consider how the meme of sustainable development was launched by the Brundtland Commission's "Our Common Future" report (World Commission on Environment and Development, 1987), and then think about how that new understanding is reiterated in memes related to sustainability, sustainable enterprise, and initiatives like the UN's Sustainable Development Goals. Or consider how the term stakeholder has gained managerial traction since Freeman's (1984) publication of his seminal book, Strategic Management: A Stakeholder Approach, as a counterpoint to the dominant shareholder-based perspective of the firm. Contrast these emerging memes with today's dominant economic narrative and memes, which are shaped by what is known as neoclassical economics and the underlying neoliberal narrative (e.g., Hartwell, 1995). This narrative contains memes of maximizing (only) shareholder wealth, free markets, free trade, self-interest, and the like. The reshaping of these memes and the narratives they support thus becomes an important part of the sensemaking role of the shamanic leader.

\section{Healer of Relationships}

Performing the three functions of the shaman-healing, connecting, and sensemaking - arguably enables leaders to operate from a more systemic and holistic point of view. They may even tackle issues that other leaders may be hesitant to grapple with, because shamans are also risk-takers. Frost \& Egri (1994) point out that shamans strive for holistic balance. Such leaders seek an integrated mind, body, heart, soul, and spirit connection at the individual level (see, e.g., Leonard \& Murphy, 1995; Wilber, Patten, Leonard, \& Morelli, 2008) and a holistic, sustainable, and socially just business or world at a more macro level. That is, leaders as shamans seek balance that is much needed at all levels of analysis in today's world.

Consider this definition: "A shaman is a healer of relationships between mind and body, between people, between people and circumstances, between humans and Nature, and between matter and spirit" (Kahili King, 2009: 14). Furthermore, the shaman "describes a particular type of practitioner who attends to the psychological and spiritual needs of a community that has granted that practitioner privileged status" (Krippner, 2002: 963) much in the same way as privileged status is granted to today's leaders. Shamanic practitioners 
"use this [privilege] in attempts to meet the needs of this group and its members" (Krippner, 2002: 963), just as leaders are expected to do when they are operating in difficult contexts. Many leaders are already taking on these roles; being a shamanic leader simply means doing so explicitly.

Some people have negative connotations associated with shamans. Early researchers and scholars, for instance, thought that they were mentally ill or tricksters. On the contrary, however, traditional shamans have been found to be healthier (Boyer, Klopfer, Brawer, \& Kawai, 1964), more creative and freer (Fabrega \& Silver, 1973), highly skilled and talented (Walsh, 2001; Basilov, 1997; Sandner, 1997), and less anxious (Van Ommeren et al., 2002) than non-shaman counterparts (all reported in Krippner, 2002). If such attributes also apply to shamanic leaders, they might be something that leaders should strive to acquire, because the world arguably needs many more leaders to work toward healing its many fractures and rifts.

\section{LEADER AS SHAMAN}

Modern Western cultures tend to draw on the Cartesian split between mind and body, material and spiritual, and focus in on atomistic and fragmented forms of understanding rather than on the shaman's more holistic, nature-based, and connected sense of spirit in all. Business as well as academic perspectives are often rooted in narrow conceptions of science, disciplinary specialization, and atomistic thinking. Such perspectives seem to have little room-or tolerance-for the ways of the shaman, who tends to be purpose/healing driven, holistic, and integrative of multiple ways of seeing and knowing, crossing numerous boundaries in the process (Waddock, 2015a). Thus, while shamans have been found in virtually all cultures of the world (Eliade, 1974), they are in little obvious evidence in most modern institutions. The idea of shaman is hardly accepted in mainstream business today, despite the healing that they may provide. There are, however, numerous popular books on the topic (e.g., Harner, 1990; Villoldo, 2007; Kahili King, 2009; Walsh, 2014), a rich and deep body of anthropological and sociological literature, and a widespread interest in the idea of shamanism among spiritually-oriented individuals. We all probably know some leaders who already perform the healing, connecting, and sensemaking roles of the shaman to serve their enterprises and the world, each in their own ways.

Shamanic leaders in all sectors, explicitly aiming to heal and make the world a better place, keep the idea of building a better world firmly in mind as part of their enterprises' core purpose. Through the connecting 
function, they bridge into new territories by crossing a variety of boundaries, engaging with different stakeholders. They creatively bring actors together in new ways that can lead to new business models and ideas, product innovations, and organizational developments which others cannot achieve. Through developing and inspiring new visions, they help others make better sense of the world.

One person who seems to fill shamanic roles is Unilever's chief executive officer, Paul Polman, who is noted for his transformative efforts in moving the giant consumer goods company toward sustainability. Polman, whatever flaws he might have as a human being, is termed by Gareth Bell as "the archetypal modern leader [who] ... combines an astuteness derived from a quarter century at Proctor and Gamble ... with a social conscience and sense of duty ..." (Bell, 2013: 38). He can also be considered a shamanic leader, even though he might not recognize the term.

By shifting memes and the company's internal narrative, not to mention the way it is perceived by external observers, Polman eliminated quarterly reporting to discourage short-termism and an overemphasis on shareholders to the detriment of other stakeholders. He re-focused the company on improving the lives of its customers sustainably and equitably, and has aimed at making it a sustainable enterprise through development of what the company calls its "Sustainable Living Plan" (Bell, 2013; Bansal \& DesJardine, 2014). The visionary CEO understands the complexities of the future, and clearly understands the connections between how the company operates and the wellbeing of its customers, stating in print that as "a company we need to focus ruthlessly on improving the lives of consumers in a sustainable and equitable way. If we do that well, shareholders will be rewarded" (quoted in Bell, 2013: 38).

Furthermore, Polman is clear about the roles companies need to play in healing the world, as well as the connections that need to be made in doing so. In an interview, he pointed out that Unilever is

... creating a much stronger ecosystem that takes our risk away, but it also creates enormous opportunities to broaden our products. Because once you work in partnerships often with governments or with civil society, it creates other opportunities to grow your business. We look at products that we otherwise would not be able to sell ... technologies in our own value chain ... [that generate] their own renewable energy .... (Polman, 2015)

Given his ability to make sense of them in ways that other business leaders want to emulate and because they make ecological and business 
sense, the shifts that Polman initiated have systemic consequences. As he comments, "So from wherever you look-from your value chain with your suppliers, from your cost structure, from your motivation with your employees, from your innovation program-there is an angle of positive growth that is connected to climate change" (Polman, 2015: 16). Furthering the connecting function of the shaman, Polman argues that part of what needs to happen is the creation of "coalitions of likeminded people that are able to create a tipping point" (Polman, 2015: 17). Such a tipping point would enable other companies and their supply and distribution chains to join in, creating holistic or systemic change in the process.

By crossing traditional boundaries, be they spiritual or the sectoral, functional, and cultural boundaries crossed by leaders like Polman, shamans (and shamanic leaders) have opportunities to create new ways of viewing old problems that have potential for healing. Since shamans focus on healing relationships of all sorts (Kahili King, 2009), shamanic leaders are, like Polman, focused on creating holistic balance (Frost \& Egri, 1994) among different stakeholders. They emphasize better relationships with stakeholders and the Earth itself (Kahili King, 2009) for their enterprises, and not just competitive but collaborative or cooperative approaches as well. In other words, the holistic focus of the leader as shaman precludes a narrow perspective on the roles and functions of the firm. For that matter, it also precludes a strict focus on maximizing shareholder wealth which seems to be expected by financial markets today, and inherently enables the leader to see the firm in its bigger context and thus with bigger purposes.

\section{DEVELOPING SHAMANIC LEADERS FOR A BETTER FUTURE}

What does it take to become a shamanic leader? While a complete answer to that question is of course beyond the scope of this article, a wisdom perspective may provide insight to help enact in practice the three functions of healing, connecting, and sensemaking. Wisdom has been defined as the integration of moral imagination, systems understanding, and aesthetic sensibility in the service of a better world (see Waddock, 2015a). Developing practices that enhance the attributes of wisdom is therefore one way of also enhancing the skills needed by the leader as shaman. These skills include broadening perspectives and moral imagination through exposure to new situations, mindfulness practices that ask leaders to "journey" to new realms, exposure to systems thinking, and aesthetic sensibility through enhanced storytelling and other creative skills. 


\section{Broadening Perspectives and Moral Imagination}

The question is: how do we expand the wisdom of present and future leaders so that they can tackle problems facing their enterprises as well as issues in their enterprises' contexts more holistically as shamans do? This means acquiring moral imagination, i.e., the ability to see the ethical implications of a situation (Werhane, 1999, 2002, 2008). Shamans in traditional cultures often gain their understandings and insights through what are called shamanic journeys. They enter into meditative, trance, or altered states of consciousness (e.g., Eliade, 1974; Harner, 1990; Frost \& Egri, 1994; Krippner, 2002; Walsh, 2014) which are induced in a variety of ways. In the trance, the shaman travels to spiritual realms where information that is used for healing, connecting, and sensemaking purposes is accessed. As noted earlier, leaders as shamans travel-either physically, intellectually, or through interactions-across multiple boundaries as well to gain information and potential insights.

One obvious way of broadening perspectives and enhancing moral imagination is to deliberately expose future leaders (or have them expose themselves) to differences in perspectives in a variety of ways, including hands-on, experiential, and work-based learning (Raelin, 1999; Kolb, 1984). Such perspective-enhancing experiences are not particularly new, and include travel, living in and exposure to different cultures, working side-by-side with people very different from themselves, multistakeholder engagements and dialogues, and similar strategies. They also include understanding management as a humanistic and not just business calling (e.g., Amann, Pirson, Dierksmeier, Von Kimakowitz, \& Spitzeck, 2011). The key is turning these experiences from simply being fun and interesting to something more shamanic and oriented toward healing, and may lie in having the individuals who experience them reflect on them either individually or in groups of people who have experienced similar things, developing what Raelin (2003) called leaderful practice.

Leaders may need to be exposed to the three tasks of the shamanhealing, connecting, and sensemaking-and explicitly work to develop their skills in these arenas, just as traditional shamans do through their apprenticeships and related experiences. Many popular books on shamanism ask would-be shamans to engage in a variety of meditative and mindfulness practices to develop their shamanic journeying practices and related insights (e.g., Villoldo, 2007; Walsh, 2014). Such practices are aimed at healing and broadening relationships with the self, others, the community, and the world, and research today is showing that various forms of mindfulness practices can have powerful results in helping enhance awareness, health, happiness, and openness (e.g., to ideas) (e.g., 
Kabat-Zinn, 1994; Langer, 1997, 2014). They also broaden perspectives in a variety of ways, including developing a more ethical and sustainabilityfocused orientation among managers (Crilly, Schneider, \& Zollo, 2008). Indeed, Crilly et al. (2008) showed in a field experiment that mindfulness practice was successful in enhancing ethical attitudes and orientation toward corporate responsibility while traditional classroom-based approaches were not.

Being a shamanic leader is based partly on practice over time and what amounts to a lifelong journey toward enhanced awareness and healing. That can happen through the practice of mindfulness techniques of different types, or practice in the field, with others, that broadens awareness and fosters healing. In fact, while such approaches are a far cry from the traditional functional specializations offered in schools of management, there is some evidence of increasing receptiveness to such ideas (e.g., in the emergence of ideas about spirituality at work [e.g., Neal, 2013]), and thus no reason why shamanic practices of various sorts might not be included in business school curricula.

\section{Systems Thinking}

Perhaps the most important attribute of the shaman for coping in and with today's troubled leadership context is holistic or systems understanding. This skill is related to the connecting function of the shaman since it integrates information from a variety of realms, and is of course linked to enhancing the breadth of perspectives and the ability to see ethical issues in situations, i.e., what is called moral imagination (Werhane, 1999). Systems understanding can potentially enhance awareness of the issues not just within a given enterprise but also in broader institutional, societal, and ecological contexts.

Senge (2006) termed this skill "systems thinking" in the 1990 edition of his seminal book, The Fifth Discipline, and others have since argued that management education and development programs need to emphasize the holistic approaches of systems thinking and understanding (Muff, Dyllick, Drewel, North, Shrivastava, \& Haertle, 2012). In traditional cultures, the shaman is sometimes initiated through apprenticeship, sometimes receives a "calling" to shamanism, or sometimes experiences some sort of life trauma that brings him or her to the practice (Eliade, 1974). In today's culture, leaders as shamans can follow much of the same pathways. For example, a "calling" to serve the world, traumatic experiences, and apprenticeship/educational experiences can help foster a sustainability (Rimanoczy \& Laszlo, 2013) or global (Aggarwal, 2011) mindset, both of which offer systems understanding potential. Such 
holistic, integrated, and systemic ways of thinking are hallmarks of the shaman (Walsh, 2014; Waddock, 2015a), and are demanded much by both enterprises and critics of management education (e.g., Muff et al., 2012).

Just as it means connecting across different domains, becoming a shamanic leader definitely requires developing a healing orientation toward the world, the organization, and its stakeholders, as well as healing the self (Waddock, 2015a). This means that leaders need to be educated about issues facing the system. They need to have a realistic understanding of the ways in which their particular institutions influence the system both positively and negatively. Leaders need to understand their own role(s) in the current system and in the desired one. Such an integrated perspective can help in developing a more holistic understanding of how the system works. It can illuminate what the dynamics, pressures, and forces are that cause the system and its various enterprises to behave the way they do, and where leverage points for change (Meadows, 1999; Senge, 2006) can be developed. Here the connecting function of the shaman can be helpful. By going outside of their everyday reality and discovering what people in different types of enterprises or institutions perceive and think, and by incorporating those new realities into their thinking, leaders can broaden their vision and begin to see things in new ways.

\section{Storytelling/Narrative Development}

Aesthetic sensibility clearly relates to the creative demands on leaders today to articulate new visions for their enterprises, help frame new understandings when changes are needed, and design enterprises and whole systems that are things of beauty. The art associated with sensemaking is clearly implicated here, as well as a sense in which leaders today need to understand the importance (and learn the skill) of storytelling, of narrative, in shaping how stakeholders perceive their enterprises. That, in effect, is what visioning and strategy-making is all about. It is the core element in the sensemaking function of the shaman. For example, visioning and storytelling skills, part of aesthetic sensibility, are clearly evident in the ways Paul Polman speaks about his vision for Unilever, notable even in the short quotes above.

In the context of the sustainability and climate change crises, many stakeholders, including employees, customers, activists, and government representatives, may no longer be satisfied by the "story" that the sole and whole focus of a firm is to "maximize shareholder wealth." They may want to see some sort of new narrative or story about the firm that identifies a broader purpose. Of course, such a narrative needs to be backed up by the kinds of actions that Polman is taking at Unilever, 
one which places the firm at the forefront of change toward a more sustainable enterprise or dealing more effectively with carbon emissions.

\section{CONCLUSION}

Business as usual will not suffice in today's troubled context, and so leaders acting as shamans are arguably needed more than ever. Today's leader as shaman needs to be oriented to today's world and needs, and not just to traditional business concerns. The needs of the present are different from what humanity has ever experienced before, and the problems-e.g., climate change, sustainability, species extinction, materialism and excessive consumption, the role of financial institutions-are too frequently beyond the scope of any one institution to resolve. Thus, today's accepted ways of thinking and acting will not move the world toward the sustainability and wellbeing embedded in the shaman's vision. Ironically, practices rooted in ancient traditions just might be able to help-and they are not so far from the ways which many leaders are already practicing. They simply need to be made explicit. The world needs, in short, more leaders to act as shamans by taking on the healing, connecting, and sensemaking tasks in the service of a better world.

\section{REFERENCES}

Ackoff, R. 1974. Redesigning the future. New York: Wiley.

Aggarwal, R. 2011. Developing a global mindset: Integrating demographics, sustainability, technology, and globalization. Journal of Teaching in International Business, 22(1): 51-69.

Álvarex, P. (Ed.). 2011. Healing a broken world: Task force on ecology. Promotio Iustitia, No. 106, 2011/2. Available at http://www.sjweb.info/documents/sjs/ pjnew/PJ106ENG.pdf.

Amann, W., Pirson, M., Dierksmeier, C., Von Kimakowitz, E., \& Spitzeck, H. 2011. Business schools under fire: Humanistic management education as the way forward. New York: Palgrave Macmillan.

Bansal, P., \& DesJardine, M. R. 2014. Business sustainability: It is about time. Strategic Organization, 12(1): 70-78.

Basilov, V. 1997. Shamans and their religious practices from shamanisms among the Turkick peoples of Siberia. In M. M. Balzar (Ed.), Shamanic worlds: Rituals and lore of Siberia and Central Asia: 3-48. Armonk, NY: North Castle Books.

Bell, G. 2013. Doing well by doing good: An interview with Paul Polman, CEO of Unilever, part 1. Strategic Direction, 29(4): 38-40.

Blackmore, S. 2000. The meme machine (vol. 25). Oxford, UK: Oxford Paperbacks. 
Boyer, L. B., Klopfer, B., Brawer, F. B., \& Kawai, H. 1964. Comparisons of the shamans and pseudoshamans of the Apaches of the Mescalero Indian Reservation: A Rorschach study. Journal of Projective Techniques \& Personality Assessment, 28(2): 173-180.

Churchman, C. W. 1967. Wicked problems. Management Science, 14(4): B141-B142.

Crilly, D., Schneider, S. C., \& Zollo, M. 2008. Psychological antecedents to socially responsible behavior. European Management Review, 5(3): 175-190.

Dawkins, R. 2006. The selfish gene. London: Oxford University Press.

Dow, J. 1986. Universal aspects of symbolic healing: A theoretical synthesis. American Anthropologist, 88(1): 56-69. Available at http://www.jstor.org/ stable/679279.

Ehrenfeld, J., \& Hoffman, A. 2013. Flourishing: A frank conversation about sustainability. Palo Alto: Stanford University Press.

Eliade, M. S. 1974. Archaic techniques of ecstasy. Princeton: Princeton University Press.

Fabrega, H., \& Silver, D. B. 1973. Illness and shamanistic curing in Zinacaantan: An ethnomedical analysis. Stanford, CA: Stanford University Press.

Freeman, R. E. 1984. Strategic management: A stakeholder approach. Boston: Pitman. Republished 2010. Cambridge, UK: Cambridge University Press.

Frost, P. J., \& Egri, C. P. 1994. The shamanic perspective on organizational change and development. Journal of Organizational Change Management, 7(1): 7-22. DOI: http://dx.doi.org/10.1108/09534819410050777.

Gilding, P. 2011. The great disruption: How the climate crisis will transform the global economy. London/New York: Bloomsbury Publishing.

Harner, M. 1990. The way of the shaman. New York: HarperOne.

Hartwell, R. M. 1995. A history of the Mont Pelerin Society. Indianapolis, IN: Liberty Fund.

IPCC. 2014. Summary for policymakers. In C. B. Field, V. R. Barros, D. J. Dokken, K. J. Mach, M. D. Mastrandrea, T. E. Bilir, M. Chatterjee, K. L. Ebi, Y. O. Estrada, R. C. Genova, B. Girma, E. S. Kissel, A. N. Levy, S. MacCracken, P. R. Mastrandrea, \& L. L. White (Eds.), Climate change 2014: Impacts, adaptation, and vulnerability. Part A: Global and sectoral aspects. New York: Cambridge University Press.

Jung, C. G. 1936. The concept of the collective unconscious. Collected Works, 9(1): 42. Available at http://www.bahaistudies.net/asma/The-Concept-of-theCollective-Unconscious.pdf.

Jung, C. G. 1981. The archetypes and the collective unconscious (No. 20). Princeton, NJ: Princeton University Press.

Kabat-Zinn, J. 1994. Wherever you go, there you are: Mindfulness meditation in everyday life. New York: Hyperion.

Kahili King, S. 2009. Urban shaman. New York: Simon and Schuster.

Kolb, D. A. 1984. Experiential learning: Experience as the source of learning and development, vol. 1. Englewood Cliffs, NJ: Prentice-Hall.

Krippner, S. C. 2002. Conflicting perspectives on shamans and shamanism: Points and counterpoints. American Psychologist, 57(11): 962-972. 
Langer, E. J. 1997. The power of mindful learning. Addison-Wesley/Addison Wesley Longman.

Langer, E. J. 2014. Mindfulness. Boston: Da Capo Press.

Leonard, G., \& Murphy, M. 1995. The life we are given: A long-term program for realizing the potential of body, mind, heart and soul. New York: Tarcher (Putnam).

Meadows, D. 1999. Leverage points: Places to intervene in a system. Harland, VT: The Sustainability Institute. Available at http://donellameadows.org/archives/ leverage-points-places-to-intervene-in-a-system/.

Muff, K., Dyllick, T., Drewel, M., North, J., Shrivastava, P., \& Haertle, J. 2012. The 50+20 agenda: Management education for the world. Available at http://50plus20.org/wp-content/uploads/2012/06/5020_AGENDA_PRINT_a4_ English.pdf.

Neal, J. A. 2013. Handbook for faith and spirituality at work. Berlin: Springer-Verlag.

Polman, P. 2015. The business of climate change. The Fletcher Forum of World Affairs, 39: 13-18.

Raelin, J. A. 1999. Work-based learning: The new frontier of management development. Reading, MA: Addison-Wesley.

Raelin, J. A. 2003. Creating leaderful organizations: How to bring out leadership in everyone. San Francisco: Berrett-Koehler.

Rimanoczy, I., \& Laszlo, E. 2013. Big bang being: Developing the sustainability mindset. Sheffield, UK: Greenleaf Publishing.

Rittel, H. W., \& Webber, M. M. 1973. Dilemmas in a general theory of planning. Policy Sciences, 4(2): 155-169.

Sandner, D. F. 1997. Introduction: Analytical psychology and shamanism. In D. F. Sandner \& S. H. Wong (Eds.), The sacred heritage: The influence of shamanism on analytical psychology: 3-11. New York: Routledge.

Senge, P. M. 2006. The fifth discipline: The art and practice of the learning organization. New York: Broadway Business.

Van Ommeren, M., Komproe, I., Cardena, E., Thapa, S. B., Prasain, D., de Jong, J. T. V. M. et al. 2002. Psychological profile of Bhutanese shamans. Paper presented at the annual conference of the Society for the Anthropology of Consciousness, Tuscon, AZ. Reported in Krippner (2002).

Villoldo, A. 2007. Shaman, healer, sage: How to heal yourself and others with the energy medicine of the Americas. New York: Harmony (Random House).

Waddell, S., Waddock, S., Cornell, S., Dentoni, D., McLachlan, M., \& Meszoely, G. 2015. Large systems change: An emerging field of transformation and transitions. Journal of Corporate Citizenship, 58: 5-30.

Waddock, S. 2015a. Intellectual shamans: Management academics making a difference. Cambridge, UK: Cambridge University Press.

Waddock, S. 2015b. Reflections: Intellectual shamans, sensemaking, and memes in large system change. Journal of Change Management, 15(4): 259-273.

Walsh, R. 2001. Shamanic experiences: A developmental analysis. Journal of Humanistic Psychology, 41(3): 31-52.

Walsh, R. 2014. The world of shamanism: New views of an ancient tradition. Woodbury, MN: Llewellyn Publications. 
Weick, K. E., Sutcliffe, K. M., \& Obstfeld, D. 2005. Organizing and the process of sensemaking. Organization Science, 16(4): 409-421.

Werhane, P. H. 1999. Moral imagination and management decision making. New York: Oxford University Press.

Werhane, P. H. 2002. Moral imagination and systems thinking. Journal of Business Ethics, 38: 33-42.

Werhane, P. H. 2008. Mental models, moral imagination and system thinking in the age of globalization. Journal of Business Ethics, 78: 463-474.

Wilber, K., Patten, T., Leonard, A., \& Morelli, M. 2008. Integral life practice: A 21st century blueprint for physical health, emotional balance, mental clarity and spiritual awakening. Integral Books.

World Commission on Environment and Development. 1987. Our common future. Oxford: Oxford University Press, 1987. 